\title{
EDITORIAL
}

\section{A simple step to reduce radiation exposure in the NICU}

\author{
Journal of Perinatology (2014) 34, 331-332; doi:10.1038/jp.2013.147
}

In this issue of the Journal of Perinatology, Scott et al. ${ }^{1}$ provide one of many recent studies to quantify $\mathrm{X}$-ray exposure in the neonatal intensive care unit (NICU). It is unique because it quantifies exposure for an entire NICU population $<33$ weeks' gestation over a 5 -year period. In that regard, it is a relatively large undertaking and represents one of the best available snapshots of X-ray exposure reality in the NICU. However, the topic of fetal and infant radiation exposure has a long and somewhat soiled history. The field of neonatology would do well to pause for a moment and reflect upon it.

Sir Richard Doll was knighted because of his work in radiation biology and epidemiology, even as he took large sums of industry money for his contributions to help discredit the concept that radiation risk for cancer was a linear function that stopped at zero exposure (a concept that Alice Stewart fought her whole life to prove). ${ }^{2}$ The two spent most of their careers locked in a very public battle trying to determine whether the atomic bombs dropped over Japan caused an increase in infant leukemia. Doll was largely credited with having won the argument. However, after Chernobyl there was a resurgence of data in favor of Stewart's hypothesis (with notable exceptions in Finland and Sweden, where some of the greatest exposure occurred). ${ }^{2}$ We still do not know if there is an absolute lower limit below which radiation is safe, but if there is one, it is extremely low because even elevations in ambient gamma radiation have been found to be associated with increased incidence of cancer. ${ }^{3}$ At the same time, the concept that cancer risk can be estimated as a linear continuum to radiation exposure is also incorrect because at higher levels the risk is well documented to become exponential for certain types of cancer. ${ }^{4}$ The truth is rarely simple, but much of what Dr Stewart fought to prove is now widely accepted and utilized in day to day practice for limiting radiation exposure.

Today, we are seeing an increasing number of publications related to quantification and quality improvement of radiation exposure, including in the NICU environment. Recent publications showing associations between computed tomography (CT) exposure and cancer incidence have increased the concern that medical radiation is a real risk. ${ }^{5,6}$ Likewise, older eras of fetal and pediatric medical X-ray exposure have documented concerning levels of exposure and cancer association. ${ }^{7-10}$ Our field should focus on this safety issue as we move to more standardized care of our patients. At the same time, we are wary of the potential for this topic to be sensationalized as it was in the last century.

The Scott et al. ${ }^{1}$ study shows us, perhaps predictably, that a fifth of our patients exceed what are considered safe levels of cumulative medical radiation exposure. These at-risk patients were generally the very smallest, least mature and/or the sickest patients in the NICU. We recognize that these are the hardest patients to reduce radiation exposure in and may be the ones with the greatest subsequent risk due to multiple risk factors..$^{11,12}$ We also note that the Scott et al. ${ }^{1}$ numbers are roughly consistent with other similar studies.

Scott et al. ${ }^{1}$ suggest 'around the clock' ultrasound as an alternative to standard $\mathrm{X}$-rays for many of the investigations responsible for the radiation these patients receive (central line placement, necrotizing enterocolitis surveillance, etc.). We agree that ultrasound is likely to gain ground as the radiologic tool of choice in the NICU and reduction of radiation exposure is one of the main reasons. In many cases ultrasound is proving superior to conventional X-ray such as monitoring the evolution of NEC or evaluating lung disease. ${ }^{13-15}$ However, NICUs today are struggling just to keep enough respiratory therapists and nurses at the bedside due to financial constraints. For most hospitals, around the clock ultrasound support or the need for additional ultrasound technicians due to increased utilization will be yet another salary line that hospital administrators are unlikely to support.

We would like to offer an alternative suggestion. There is growing recognition of the need to recalibrate neonatology fellowship training toward stronger clinical focus. One change could be for fellows to undertake formal ultrasound training. We note that we are not the first to suggest that ultrasound be a part of neonatal fellowship. ${ }^{16,17}$ This change would probably do more to move neonatology away from dependence on conventional X-rays than any other single intervention or policy change. Likewise, at a time when neonatal skills training has been undermined by reductions in NICU experience during pediatric residency (thus truncating the cumulative neonatal fellow's NICU experience), ${ }^{18-25}$ adding this useful tool to the neonatal skills arsenal could be an important first step toward a better trained neonatologist.

\section{CONFLICT OF INTEREST}

The authors declare no conflict of interest.

$$
\begin{array}{r}
\text { PV Gordon' }{ }^{1} \text { and JR Swanson }{ }^{2} \\
{ }^{1} \text { Pediatrix, Sunrise FI and Sacred Heart Womens and } \\
\text { Infants Hospital, Pensacola, FL, USA and } \\
{ }^{2} \text { Department of Pediatrics, University of Virginia, } \\
\text { Charlottesville, VA, USA } \\
\text { E-mail: pgordon1@tulane.edu }
\end{array}
$$

\section{REFERENCES}

1 Scott MV, Fujii AM, Behrman RH, Dillon JE. Diagnostic x-ray exposure in premature patients. J Perinatol 2013.

2 Greene G. Richard Doll and Alice Stewart: reputation and the shaping of scientific "truth". Perspect Biol Med 2011; 54(4): 504-531.

3 Pukkala E, Auvinen A, Wahlberg G. Incidence of cancer among Finnish airline cabin attendants, 1967-92. BMJ 1995; 311: 649-652.

4 Brown MJ. Linearity vs non-linearity of dose response for radiation carcinogenesis. Health Phys 1976; 31(3): 231-245.

5 Hall EJ. Lessons we have learned from our children: cancer risks from diagnostic radiology. Pediatr Radiol 2002; 32(10): 700-706.

6 Linet MS, Kim KP, Rajaraman P. Children's exposure to diagnostic medical radiation and cancer risk: epidemiologic and dosimetric considerations. Pediatr Radiol 2009; 39(Suppl 1): S4-26.

7 Stewart AM, Webb J, Giles D, Hewitt D. Malignant disease in childhood and diagnostic irradiation in utero. Lancet 1956; 271(6940): 447.

8 Stewart A, Webb J, Hewitt D. A survey of childhood malignancies. Br Med J 1958; 1: 1495-1508.

9 Brenner DJ, Elliston CD, Hall EJ, Berdon WE. Estimated risks of radiation-induced fatal cancer from pediatric CT. AJR Am J Roentgenol 2001; 176: 289-296.

10 Wakeford R. Childhood leukaemia following medical diagnostic exposure to ionizing radiation in utero or after birth. Radiat Prot Dosimetry 2008; 132: 166-174. 
11 Crump C, Sundquist K, Winkleby MA, Sieh W, Sundquist J. Gestational age and risk of testicular cancer. Int J Cancer 2012; 131(2): 446-451.

12 Schmidt LS, Schuz J, Lahteenmaki P, Trager C, Stokland T, Gustafson G et al. Fetal growth, preterm birth, neonatal stress and risk for CNS tumors in children: a Nordic population- and register-based case-control study. Cancer Epidemiol Biomarkers Prev 2010; 19(4): 1042-1052.

13 Shebrya NH, Amin SK, El-Shinnawy MA, Imam SS. Abdominal ultrasonography in preterm necrotizing enterocolitis: is it superior to plain radiography? Egypt J Radiol Nuc Med 2012; 43(3): 457-463.

14 Silva CT, Daneman A, Navarro OM, Moineddin R, Levine D, Moore AM. A prospective comparison of intestinal sonography and abdominal radiographs in a neonatal intensive care unit. Pediatr Radiol 2013; 43(11): 1453-1463.

15 Lictenstein DA, Mauriat P. Lung ultrasound in the critically ill neonate. Curr Pediatr Rev 2012; 8(3): 217-223.

16 Evans N, Gournay V, Cabanas F, Kluckow M, Leone T, Groves A et al. Point-of-care ultrasound in the neonatal intensive care unit: international perspectives. Semin Fetal Neonatal Med 2011; 16(1): 61-68.

17 Burdjalov V, Srinivasan P, Baumgart S, Spitzer AR. Handheld portable ultrasound in the neonatal intensive care nursery: a new, inexpensive tool for the rapid diagnosis of common neonatal problems. J Perinatol 2002; 22(6): 478-483.
18 Falck AJ, Escobedo MB, Baillargeon JG, Villard LG, Gunkel JH. Proficiency of pediatric residents in performing neonatal endotracheal intubation. Pediatrics 2003; 112: (6Pt1) 1242-1247.

19 Leone TA, Rich W, Finer NN. Neonatal intubation: success of pediatric trainees. J Pediatr 2005; 146(5): 638-641.

20 O'Donnell CP, Kamlin CO, Davis PG, Morley CJ. Endotracheal intubation attempts during neonatal resuscitation: success rates, duration, and adverse effects. Pediatrics 2006; 117(1): e16-e21.

21 Gaies MG, Landrigan CP, Hafler JP, Sandora TJ. Assessing procedural skills training in pediatric residency programs. Pediatrics 2007; 120(4): 715-722.

22 Downes KJ, Narendran V, Meinzen-Derr J, McClanahan S, Akinbi HT. The lost art of intubation: assessing opportunities for residents to perform neonatal intubation. J Perinatol 2012; 32(12): 927-932.

23 Antiel RM, Thompson SM, Hafferty FW, James KM, Tilburt JC, Bannon MP et al. Duty hour recommendations and implications for meeting the ACGME core competencies: views of residency directors. Mayo Clin Proc 2011; 86(3): 185-191.

24 Ryan RM, Brion LP, Aucott SW, Juul SE, Parker TA, Savich RD et al. Organization of Neonatal Training Program Directors Council responds to the ACGME 2010 Proposed Standards. J Perinatol 2011; 31(4): 296-297.

25 Gordon PV. A moment of Silence.... e-Journal of Neonatology Research 2012; 2(3): 138-141. 